\title{
COMENTARIO DE SENTENCIAS DICTADAS EN SEDE DE PROTECCIÓN DE LOS DERECHOS DE LOS CONSUMIDORES SOBRE ZAPATILLAS TERAPÉUTICAS
}

COMMENT ON JUDGMENTS ABOUT THERAPEUTIC SLIPPERS

CONSUMERS' RIGHTS

COMMENTAIRE DES ARRÊTS DANS LE DOMAINE DE LA PROTECTION

DES DROITS DES CONSOMMATEURS À PROPOS DES CHAUSSURES

THÉRAPEUTIQUES

Erika Marlene Isler Soto*

\section{ANTECEDENTES DEL CASO}

Con frecuencia se advierte en el mercado el ofrecimiento de ciertos productos, a los cuales se les atribuyen propiedades terapéuticas. A modo de ejemplo, ya en los años 2011 y 2012 nuestros Tribunales se habían pronunciado sobre esta temática, al conocer de las dos denuncias interpuestas por el Servicio Nacional del Consumidor por la oferta y comercialización de ciertas pulseras, cuyo solo uso tendría la virtud de generar efectos beneficiosos para la salud ${ }^{1}$. En ambos casos, las sentencias fueron condenatorias.

Recientemente -2013- el mismo Servicio accionó en contra de aquellos proveedores que ofrecieron y comercializaron ciertas líneas de zapatillas, las cuales -de acuerdo a los anunciantes- se habrían encontrado diseñadas con una suela curva, la cual ayudaría a los consumidores a mejorar su estado físico.

El primer caso, "Sernac con Skechers Chile Ltda." referida a las zapatillas "Shape $U p s$ ". En ella se indicaba que dichos productos tenían los siguientes atributos: simular la sensación de caminar sobre la arena; quemar

\footnotetext{
*Abogado; Licenciada en Ciencias Jurídicas y Sociales de la Universidad Austral de Chile. Magíster en Derecho, mención Derecho Privado, por la Universidad de Chile. Magíster en Ciencia Jurídica por la Pontificia Universidad Católica de Chile. Doctor en Derecho (C), Pontificia Universidad Católica de Chile; Becaria Conicyt. Profesora de Derecho del Consumidor, Universidad Gabriela Mistral; Profesora de Derecho Civil y Derecho del Consumidor, Universidad Bernardo O’Higgins. Correo electrónico: erikaisler@yahoo.es.

${ }^{1}$ Segundo JPL Providencia, "Sernac con Inversiones Pastrami S.A.", 15 de junio de 2012, Rol No 15.361F-2010; Primer JPL Las Condes, "Sernac con Cencosud Retail S.A.", 31 de mayo de 2011, Rol No 43.1098-2010, confirmada por la Corte de Apelaciones de Santiago, 7 de marzo de 2012, Rol No 1687-2011.

${ }^{2}$ JPL Vitacura, "Sernac con Skechers Chile Ltda.", 29 de agosto de 2012, Rol No 269.840-8-2011, confirmada por la Corte de Apelaciones de Santiago, 2 de octubre de 2013, Rol No 148-2013.
} 
más calorías que las zapatillas normales; proteger las articulaciones; absorber de mejor manera el impacto; tonificar y fortalecer los músculos; aumentar la actividad muscular; y corregir la postura ${ }^{3}$. Acompañaban dichas expresiones, imágenes de atractivas mujeres en una actitud física saludable.

Algo similar ocurrió en la causa "Sernac con Cencosud Retail S.A." ocasión, se promocionó a las zapatillas Perfect Steps y Slim Step, atribuyéndoseles las siguientes cualidades: "mejorar la salud, lograr una figura ideal, de tonificación, perder peso caminando, etc." 5 .

En ambos casos, el Servicio Nacional del Consumidor interpuso denuncias infraccionales en contra de los proveedores indicados, por vulneración de las normas sobre información y publicidad contenidas en la Ley No $19.496^{6}$.

De acuerdo al organismo público, Skechers Chile Ltda. ${ }^{7}$ habría vulnerado la LPC, al generar en los consumidores expectativas que no necesariamente verían satisfechas. En este caso, además la publicidad haría alusión a que el uso de estos productos podría reemplazar un entrenador personal ("Bye bye trainer. Hello shape Ups"). Además acompañó al juicio, publicaciones de prensa en las cuales se indicaba que la Comisión Federal de Comercio de Estados Unidos habría acusado a esta empresa por publicidad engañosa, en el ofrecimiento de esta misma línea de productos, lo cual habría motivado una posterior prohibición de difundir las promesas publicitarias en cuestión, salvo que ellas fueren comprobables científicamente.

La denunciada por su parte, se defendió argumentando que en ningún momento había infringido las normas invocadas por el organismo público, puesto que las aseveraciones publicitarias cuestionadas se fundamentaban en ciertos estudios técnicos que acompañó al juicio. Dicha tesis fue finalmente rechazada tanto por el Tribunal de primera como de segunda instancia, quienes condenaron a la empresa al pago de una multa infraccional a beneficio estatal.

\footnotetext{
3“(...) Shape Ups incorporan una suave cuña cinética que junto con su suela curva, simulan la sensación de caminar sobre arena (...)"; "Quema más calorías, protege tus articulaciones. Siente como si estuvieras corriendo en la arena"; "Están diseñadas para ayudar a absorver impacto y aumentar la actividad muscular gracias a la tecnología shape ups (...) Tonifica y fortalece los músculos. Quema más calorías. Corrige la postura. Obtén más de tu rutina de ejercicio con Shape Ups".

${ }^{4}$ Primer JPL Las Condes, “Sernac con Cencosud Retail S.A.”, 22 de enero de 2013, Rol No 22.197-8-2011.

5 "Perfect Steps, mejora la salud y permite lograr una figura ideal". Además se indica que el uso de dichos productos tonifica el cuerpo al caminar; mejora la figura, la tonicidad del abdomen, piernas, pantorrillas, espalda y glúteos; estimula y tonifica músculos; previene dolores corporales; activa músculos de las piernas y mejora la circulación previniendo várices y celulitis; aumenta en $5 \mathrm{~cm}$. la estatura, etc.; activa los músculos y quema calorías.

${ }^{6}$ Ley $\mathrm{N}^{\circ} 19.496$, establece normas sobre protección de los derechos de los consumidores, Diario Oficial, 7 de marzo de 1997.

${ }^{7}$ JPL Vitacura, "Sernac con Skechers Chile Ltda.", 29 de agosto de 2012, Rol No 269.840-8-2011, confirmada por la Corte de Apelaciones de Santiago, 2 de octubre de 2013, Rol No 148-2013.
} 
También condenatoria fue la sentencia "Sernac con Cencosud Retail S.A." , en la cual el Tribunal tampoco acogió la defensa de la denunciada, quien aseguraba haber respetado en todo momento la Ley No 19.496, por cuanto la publicidad emitida no atribuía cualidades ni aseguraba un resultado determinado por el uso de las zapatillas. Indicó que sólo se anunciaba el precio, modo de adquisición y la circunstancia de que la suela curva de las zapatillas fortalecía algunos músculos del cuerpo humano. Prueba de lo anterior, era la ausencia total de reclamos de consumidores eventualmente afectados.

\section{HipÓtesis INFRACCIONALES INVOLUCRADAS}

\subsection{La vulneración del derecho a una información veraz y oportuna}

Conforme al artículo $3^{\circ}$ letra b) LPC, el consumidor es titular del derecho básico ${ }^{9}$ a una información veraz y oportuna sobre los bienes y servicios ofrecidos, su precio y condiciones de contratación.

La consagración de esta garantía tiene por objeto, en primer lugar, hacer disminuir la asimetría informativa existente entre proveedores y consumidores ${ }^{10}$, "favoreciendo de esta manera una formación de la voluntad más adecuada de estos últimos y, por lo tanto, una elección más libre de los bienes y servicios"11.

Desde este punto de vista, la satisfacción del derecho a una información veraz y oportuna, tutela no sólo las demás garantías básicas del mismo artículo 3 LPC -a la libre elección, salud, seguridad, educación-, sino que también otras prerrogativas que este cuerpo normativo otorga a los consumidores en otras disposiciones.

En el caso que se comenta nos encontramos frente a un producto que no cumple necesariamente con las expectativas que pudieran generarse en el receptor de la publicidad, tornándose en defectuoso inapto por adolecer de un vicio de

\footnotetext{
${ }^{8}$ Primer JPL Las Condes, “Sernac con Cencosud Retail S.A.”, 22 de enero de 2013, Rol No 22.197-8-2011.

${ }^{9}$ Las normativas protectoras de los consumidores suelen consagrar ciertas garantías a las que califican de "básicas", y que en general se encuentran ubicadas en su parte preliminar. La importancia de que un derecho tenga este carácter, radica fundamentalmente en sus titulares: mientras la doctrina atribuye al consumidor abstracto -todos los ciudadanos en cuanto a personas- los derechos básicos, al consumidor concreto -aquel que efectivamente ha intervenido con el proveedor en un caso particular- se le conceden de manera adicional, otras prerrogativas entre las cuales se encuentran las acciones contractuales, la garantía legal, el derecho a retracto, etc. Cfr. JARA Amigo, Rony (1999). “Ámbito de aplicación de la Ley chilena de protección al consumidor: inclusiones y exclusiones”. En: Derecho del consumo y protección al consumidor. Cuadernos de Extensión No 3, Corral Talciani, Hernán (Ed.), Santiago: Facultad de Derecho Universidad de Los Andes, p. 62.

${ }^{10}$ Ruiz Tagle-Vial, Carlos (2010). Curso de Derecho Económico. Santiago: Librotecnia, p. 300.

${ }^{11}$ De la Maza Gazmuri, Íñigo (2013). “Art. 1 No 3 LPC”. En: La protección de los derechos de los consumidores, De la Maza, Íñigo y Pizarro, Carlos (Dir.), Santiago: Thomson Reuters, p. 24.
} 
información ${ }^{12}$, esto es, aquel en que "el riesgo no nace del mismo producto sino de una ausencia de la información que debía proporcionar el fabricante para su recto uso" 13 . En efecto, si no se hubiese difundido la propaganda cuestionada, las zapatillas no adolecerían de vicio alguno, puesto que servirían para su uso natural, cual es, servir para la realización de ejercicio físico. El problema se presenta cuando los anunciantes deciden atribuirles cualidades especiales, que finalmente no son comprobables, y que las hacen devenir en inútiles para el uso que justificó la celebración del contrato de compraventa.

En este sentido, precisamente se pronunció el Tribunal en la causa "Sernac con Cencosud Retail S.A.", al sostener que en este caso "no se dio cumplimiento a una información oportuna, clara y completa, debido a que nada de lo publicitado se encuentra garantizado o avalado por estudios cientificos $y /$ o por la experiencia de otros consumidores, circunstancias que tampoco han sido acreditadas por la denunciada, advirtiéndose que la publicidad cuestionada se fundamenta en resultados que no se han comprobado ni se encuentran certificados por el organismo de salud pertinente, creando expectativas en el consumidor al adquirir el producto, cuyos resultados no se encuentran garantizados"14.

Por otra parte, cabe señalar que si se interpreta el artículo $3^{\circ}$ letra b) a la luz de las demás normas de la LPC, se advierte un problema que, aunque no es tratado en las sentencias que se comentan, tiene especial relevancia a la hora de establecer los efectos de las obligaciones en materia de consumo. Éste se refiere a la posibilidad de que la vulneración de alguna de las garantías contenidas en el catálogo del artículo $3^{\circ}$ LPC -entre ellas el derecho a la información- dé origen a una infracción, o bien, si esta disposición establece una mera declaración de principios.

Conforme a una primera posible respuesta, la mera transgresión de uno de los derechos consagrados en el artículo $3^{\circ} \mathrm{LPC}$, no generaría responsabilidad infraccional, puesto que se encontrarían contenidos en una disposición ubicada en las "Disposiciones generales" (Título II) de la ley. Así las cosas, para que dicha conducta sea sancionable, debe enmarcarse además en alguna de las hipótesis contravencionales que establecen sanciones, esto es, las descritas en los artículos referentes a "Obligaciones del proveedor" (Título segundo, párrafo tercero) y "Responsabilidad por incumplimiento" (Título segundo, párrafo quinto).

Una segunda solución sería estimar que de la infracción de cualquiera de las disposiciones de la LPC -entre ellas el artículo $3^{\circ}$ LPC- se podría originar responsabilidad infraccional, cumplidos los presupuestos para ello. Se fundamenta

\footnotetext{
${ }^{12}$ Según su origen los defectos se clasifican en de fabricación, diseño, transporte, información y de desarrollo.

${ }^{13}$ Corral Talciani, Hernán (1999). "Ley de Protección al Consumidor y responsabilidad civil por productos y servicios defectuosos”. En: Derecho del consumo y protección al consumidor. Cuadernos de Extensión No 3 , Corral Talciani, Hernán (Ed.), Santiago: Facultad de Derecho Universidad de los Andes, p. 168.

${ }^{14}$ Primer JPL Las Condes, “Sernac con Cencosud Retail S.A.”, 22 de enero de 2013, Rol No 22.197-8-2011.
} 
dicho postulado especialmente en el tenor literal del artículo 50 inciso $2^{\circ} \mathrm{LPC}$, conforme al cual el incumplimiento de las normas contenidas en este cuerpo normativo -indistintamente- daría lugar a cualquiera de las acciones generales que consagra, incluida la sancionatoria ${ }^{15}$.

Así las cosas, se relaciona estrechamente esta problemática con la discusión que existe acerca de si todas las normas de la LPC son fuente de las acciones generales establecidas en el artículo 50 LPC (tesis monista), o bien si la acción infraccional proviene de la contravención de sólo algunas de ellas, y las acciones civiles provienen de otras (tesis bipartita y tripartita), cuestión que excede el campo de este comentario y respecto de la cual se puede consultar la bibliografía que existe al respecto ${ }^{16}$. Con todo, pareciera que el Servicio Nacional del Consumidor se inclina por esta tesis, en atención a que precisamente interpone la acción argumentando que la denunciada habría infringido -entre otros- el señalado artículo $3^{\circ}$ letra d) LPC.

Como se adelantó, en ninguno de los casos el Tribunal se refirió sobre esta temática, aunque sanciona con una multa que al parecer englobaría las tres infracciones denunciadas. Sobre esto se volverá más adelante.

\subsection{La vulneración de las normas sobre publicidad}

De acuerdo al artículo $1^{\circ}$ No $4 \mathrm{LPC}$, se entiende por publicidad a toda aquella “comunicación que el proveedor dirige al público por cualquier medio idóneo al efecto, para informarlo y motivarlo a adquirir o contratar un bien o servicio, entendiéndose incorporadas al contrato las condiciones objetivas contenidas en la publicidad hasta el momento de celebrar el contrato".

Nuestra Ley de Protección al Consumidor no regula todas las manifestaciones de publicidad ilícita que han sido recogidas por el Derecho Comparado, limitándose a sancionar la falsa, engañosa y algunas hipótesis de publicidad agresiva.

\footnotetext{
${ }^{15}$ Artículo 50 inciso 2० LPC: "El incumplimiento de las normas contenidas en la presente ley dará lugar a las acciones destinadas a sancionar al proveedor que incurra en infracción, anular las cláusulas abusivas incorporadas en los contratos de adhesión, obtener la prestación de la obligación incumplida, hacer cesar el acto que afecte el ejercicio de los derechos de los consumidores, a obtener la debida indemnización de perjuicios o la reparación que corresponda".

${ }^{16}$ Aimone Gibson, Enrique (1998). Derecho de protección al consumidor. Santiago: Editorial Jurídica Conosur, p. 94; Barcia Lehmann, Rodrigo (2012). "Estudio sobre la prescripción y caducidad en el Derecho del Consumo". Revista Chilena de Derecho Privado, No 19, p. 145; BARRIEntos Camus, Francisca (2011). "Algunas reflexiones sobre el desbordamiento de la responsabilidad infraccional en la Ley No 19.496". Revista Derecho de la Empresa, Universidad Adolfo Ibáñez, Santiago: Legis, No 25, pp. 55-80; Fernández Fredes, Francisco (2003). Manual de derecho chileno de protección al consumidor. Santiago: LexisNexis, pp. 23-35; Guerrero BECAR, José Luis (2008). "La distinción entre contravención infraccional e incumplimiento contractual". En: Colección de estudios de Derecho Civil en homenaje a la profesora Inés Pardo de Carvallo, GuZMÁN BRITO, Alejandro (Edit.), Valparaíso, Ediciones Universitarias de Valparaíso pp. 433-453; Guerrero BeCAR, José Luis (2013). "Art. 24 LPC”. En: La protección de los derechos de los consumidores, De LA MAZA, Íñigo Y Pizarro, Carlos (Dir.), Santiago: Thomson Reuters, p. 592; Ruiz Tagle-Vial (2010), p. 331.
} 
Lo anterior tiene importancia, puesto que a la responsabilidad infraccional -al ser sancionatoria-, se le aplica también el principio de tipicidad, conforme al cual una conducta debe encontrarse expresamente descrita en la norma para que sea punible. Desde este punto de vista, si se quiere interponer una acción por conductas no especialmente tipificadas, se debe acreditar la vulneración de otras normas, tales como los derechos básicos ( $v . g r$. el derecho a la discriminación en el caso de la publicidad abusiva).

Ahora bien, en el caso que se comenta, el Servicio Nacional del Consumidor invoca los artículos 28 letra b) y 33 LPC como fundamento de sus acciones.

De acuerdo al primero de ellos, comete infracción a la LPC, el proveedor que " $a$ sabiendas o debiendo saberlo y a través de cualquier tipo de mensaje publicitario induce a error o engaño respecto de: (...) b) la idoneidad del bien o servicio para los fines que se pretende satisfacer y que haya sido atribuida en forma explícita por el anunciante".

$\mathrm{El}$ artículo 33 inciso $1^{\circ}$ en tanto prescribe que "la información que se consigne en los productos, etiquetas, envases, empaques o en la publicidad y difusión de los bienes y servicios deberá ser susceptible de comprobación y no contendrá expresiones que induzcan a error o engaño al consumidor".

La importancia de distinguir entre una y otra dice relación, en primer término, con la determinación del quantum infraccional. Lo anterior, por cuanto la infracción al artículo 28 LPC se encuentra sancionada con una multa de hasta 750 UTM, y si afecta la salud o la seguridad de la población o del medio ambiente, puede llegar hasta 1000 UTM. Si se vulnera el artículo 33 en tanto, al no indicarse sanción específica, debe recurrirse a la norma de clausura (artículo 24 inciso $1^{\circ}$ ), esto es una multa de hasta 50 UTM.

En segundo lugar, ambas disposiciones difieren en cuanto a la exigencia de un elemento subjetivo en la persona del proveedor, por cuanto el artículo $28 \mathrm{LPC}-\mathrm{a}$ diferencia del artículo 33 LPC- exige que haya actuado a sabiendas o debiendo saber que la publicidad que emite provoca o puede provocar error o engaño en los consumidores.

En el caso que se comenta, ninguna de las sentencias se refiere a una eventual defensa del proveedor en orden a argumentar que respecto de la infracción denunciada con fundamento en el artículo 28 LPC no se ha actuado con dolo ni culpa, en cuyo caso el actor debió de haber acreditado, al menos mediante presunciones, que las denunciadas sabían o debían saber que la publicidad emitida generaría error o engaño respecto de las cualidades atribuidas explícitamente por los anunciantes. Naturalmente, el examen de negligencia en este caso debe realizarse tomando en consideración la situación de desigualdad que existe entre los contratantes, de tal manera que el nivel de diligencia o cuidado exigido al proveedor en cuanto a la información que otorga es mucho mayor a la que se espera del consumidor.

En lo que se refiere al contenido de los supuestos infraccionales, se puede advertir que el artículo 33 es más amplio que el artículo 28 , por cuanto no 
contiene un catálogo taxativo de aspectos respecto de los cuales pueda versar la publicidad falsa o engañosa, sino que basta con que provoque error o engaño al consumidor.

Así las cosas se transgredirá el artículo 28 LPC, sólo en la medida que la falsa representación de la realidad se enmarque dentro de alguna de las materias señaladas en dicha norma. En este caso concreto, la publicidad se refiere a la idoneidad de las zapatillas para satisfacer los fines que expresamente les han atribuido los anunciantes, a saber, otorgar una sensación de caminar sobre la arena, quemar más eficientemente calorías, proteger las articulaciones, tonificar los músculos, aumentar la actividad muscular y corregir la postura, entre otras.

El artículo 33 en tanto permite asociar al uso de un producto las propiedades ya indicadas, siempre que ellas fueren comprobables, lo cual no ocurriría en este caso.

En este sentido, la sentencia "Sernac con Skechers Chile Ltda.", fundamenta su condena en que los estudios científicos acompañados por la denunciada, si bien concluyen que el uso de las zapatillas de suela redonda podría eventualmente generar los efectos prometidos -conclusión que incluso podría resultar razonable-, ello no se encuentra suficientemente acreditado.

Además, señaló que la publicidad examinada "hace referencia clara y expresa a la obtención de determinados resultados con el sólo (sic) uso de esta zapatilla, cuales son la tonificación muscular, la pérdida de peso, el fortalecimiento de las articulaciones y la corrección de la postura física, insinuando claramente, que con su uso se puede reemplazar el ejercicio o entrenamiento común en gimnasios o con un entrenador personal, todo lo cual no se encuentra acreditado ni comprobado científicamente, de manera directa y clara" ${ }^{17}$.

Un criterio distinto utilizó el Primer Juzgado de Policía Local de Las Condes: aunque igualmente dicta sentencia condenatoria, no lo realiza en razón de las propiedades del producto, sino que en su calificación. En efecto, indica que independiente de si las zapatillas cumplen o no con lo prometido, las cualidades que se le atribuyen las hacen enmarcar, cuando no en el concepto que nuestro ordenamiento jurídico otorga de medicamento ${ }^{18}$, al menos en el de productos de utilidad médica, esto es, "instrumentos, aparatos, dispositivos y otros artículos o elementos destinados al diagnóstico, prevención y tratamiento de enfermedades de seres humanos, así como al reemplazo o modificación de sus anatomías" y que no correspondan a medicamentos, alimentos de uso médico o cosméticos. En razón de lo anterior, es que su ofrecimiento y comercialización debió de haber sido autorizado

\footnotetext{
${ }^{17}$ JPL Vitacura, "Sernac con Skechers Chile Ltda.", 29 de agosto de 2012, Rol No 269.840-8-2011, confirmada por la Corte de Apelaciones de Santiago, 2 de octubre de 2013, Rol No 148-2013.

${ }^{18} \mathrm{Se}$ entiende por producto farmacéutico o medicamento a "cualquiera substancia, natural o sintética, $o$ mezcla de ellas, que se destine a la administración al hombre o a los animales con fines de curación, atenuación, tratamiento, prevención o diagnóstico de las enfermedades o de sus sintomas" (Artículo 97 Código Sanitario).
} 
por la autoridad sanitaria competente ${ }^{19}$, lo cual no había ocurrido, y por tanto no era comprobable ${ }^{20}$.

Con todo, cualquiera sea la infracción publicitaria denunciada, se debe examinar el mensaje como una unidad, esto es, considerando todos los elementos que se encuentran presentes, entre ellos, expresiones, imágenes, tamaño de letra, fuentes, eventuales omisiones, posición del texto, etc. De acuerdo a lo anterior, es que no se respetaría la LPC, si el consumidor, para conocer la real aptitud del bien, debe recurrir a antecedentes externos al soporte publicitario, tal como lo manifestó el Tribunal en "Sernac con Cencosud Retail S.A.": "el aviso publicitario en cuestión debería bastarse por si (sic) mismo, debiendo ser suficiente en cuanto a su contenido a fin de proporcionar al consumidor la debida información, logrando una total transparencia, equilibrio y seguridad en las relaciones de consumo ya que con estas medidas el consumidor tiene la seguridad de que dispone toda (sic) la información necesaria para acceder a las citadas promociones" 21 .

\subsection{Efectos de las obligaciones}

El defecto de información por errónea expectativa generada a partir de un soporte publicitario puede dar origen a acciones tanto civiles como infraccionales.

Si existen consumidores afectados, ellos pueden recurrir en primer lugar a las herramientas que les otorga el derecho común, esto es, la acción redhibitoria, de resolución o de cumplimiento. En segundo término, resultan también procedentes aquellas otras que derivan de la LPC, esto es garantía legal, de cumplimiento e indemnizatoria. Se debe agregar además, que conforme al artículo $1^{\circ}$ No 4 LPC, las condiciones objetivas contenidas en la publicidad hasta el momento de la celebración del contrato de consumo, se entienden pertenecer a éste. De esta manera, sería posible que un consumidor demande a la empresa proveedora por incumplimiento contractual (artículo 12 LPC) si, habiendo utilizado el producto, no se produjeren los beneficios prometidos.

En el caso que se comenta, las acciones civiles no son interpuestas, puesto que es únicamente el Servicio Nacional del Consumidor quien acciona, en uso de la facultad que le otorga el artículo 58 letra g) LPC para ello.

En las dos sentencias revisadas, los sentenciadores acceden a la responsabilidad infraccional, condenando a los proveedores al pago de multas a beneficio estatal, aunque se varía respecto del monto: 150 UTM en "Sernac con Skechers Chile Ltda." y 10 UTM en "Sernac con Cencosud Retail S.A.".

\footnotetext{
${ }^{19}$ Artículo 54 Código Sanitario “(...) no podrán anunciarse como productos medicinales, nutritivos o de utilidad médica sino aquellos que hayan sido autorizados o reconocidos como tales por el Servicio Nacional de Salud".

${ }^{20}$ Primer JPL Las Condes, “Sernac con Cencosud Retail S.A.”, 22 de enero de 2013, Rol No 22.197-8-2011. ${ }^{21}$ Idem.
} 
Al respecto cabe señalar que, en ambos casos, llama la atención que se haya determinado una multa única o en globo, habiéndose determinado la concurrencia de tres infracciones diferentes. Lo anterior -aunque no consta en el texto de la sentencia- podría obedecer al deseo de no infringir el principio non bis in idem, al sancionar más de una vez una misma conducta, tal como en algún caso se había señalado con anterioridad ${ }^{22}$.

No obstante, dicha eventual vulneración es sólo aparente, por cuanto cada norma tiene por objeto tutelar bienes jurídicos diversos, estableciendo además presupuestos de concurrencia diferentes, por lo que no habría problema en establecer una multa por cada infracción.

Finalmente, tampoco se comparte el criterio utilizado por el Primer Juzgado de Policía Local de Las Condes, por cuanto fundamenta la cuantía en el artículo 24 inciso $1^{\circ} \mathrm{LPC}$ que es una norma supletoria, en circunstancias que el inciso $2^{\circ}$ de la misma disposición establece expresamente una multa agravada para la publicidad falsa o engañosa.

${ }^{22}$ Cuarto JPL Santiago, "Sernac con Instituto Latinoamericano de Comercio Limitada", 9 de marzo de 2009, Rol No 14.377-5-2007. 